Unemployment Benefits, Unemployment Duration, and Post-Unemployment Jobs

A Regression Discontinuity Approach

Rafael Lalive*

University of Lausanne

This version: January 9, 2007

Session title: "Social Insurance Programs: Good for Workers? Good for the Labor Market? "

Session chair: Raj Chetty, UC Berkeley

Discussant: Thomas Lemieux, University of British Columbia

JEL-Classification: C41, J64, J65

Keywords: benefit duration, unemployment duration, early retirement, regression discontinuity

Address:

Rafael Lalive

University of Lausanne

HEC/DEEP

CH-1015 Lausanne-Dorigny

Switzerland

Rafael:Lalive@unil.ch

Tel. +44216923431

Fax. +41216923305

\footnotetext{
*Address: University of Lausanne, Ecole des HEC, DEEP, CH-1015 Lausanne, Rafael.Lalive@ unil.ch, Tel: +41-21-634 3431, Fax: +41-21-63. I am also affiliated with CEPR, CESifo, IEW (University of Zurich), IFAU, and IZA.
} 


\section{Unemployment Benefits, Unemployment Duration, and Post-Unemployment Jobs A Regression Discontinuity Approach}

Structural unemployment appears to be strongly correlated with the potential duration of unemployment across OECD countries (Stephen Nickell and Richard Layard, 1999). The idea is that extended benefit duration discourages job search and thus leads to prolonged unemployment duration. This paper proposes to test this idea by studying discontinuous changes in benefit duration at age 50 years which are embedded in the Austrian unemployment insurance system. In particular, job seekers who satisfy a previous work requirement are eligible for 52 weeks rather than 39 weeks of extended benefits if they enter unemployment aged 50 years or older. Moreover, due to special restructuring demands in the state owned steel sector, Austria temporarily implemented a regional extended benefit program (REBP) covering job seekers were aged 50 or older when entering unemployment, who had been living for at least 6 months in certain regions of Austria, who satisfy a previous work requirement. Those individuals were eligible to 209 weeks of benefit duration instead of 39 weeks of benefit duration. Austrian unemployment insurance rules create a rich design allowing to study the effects of small increases of benefit duration by 13 weeks (39 to 52 weeks) in regions that were excluded from the extended benefit program and large benefit extensions by 170 weeks (39 weeks to 209 weeks) in regions with access to the extended benefit program. Because these benefit entitlement rules were discontinuous in age, the corresponding causal effects can be identified in a regression discontinuity framework.

This paper contributes to two strands of the literature. The first strand is concerned with measuring the effects of potential benefit duration on unemployment duration. Recent contributions to this literature include David E. Card and Phillip B. Levine (2000); Rafael Lalive and Josef Zweimüller (2004a); Jan C. van Ours and Milan Vodopivec (2006b); Card, Raj Chetty and Andrea Weber (2006). The main finding in this literature is that extended 
benefits increase unemployment duration. The second strand of the literature is concerned with measuring the effects of the unemployment insurance system on the quality of postunemployment jobs. Two recent studies include Van Ours and Vodopivec (2006a); Card, Chetty, and Weber (2006). Both studies do not find any effect of the potential benefit duration on the quality of post unemployment jobs.

This paper goes beyond the existing literature in providing evidence on the effects of very large and small benefit extensions. Whereas the existing literature has analyzed the effects of changing benefit duration by one or two quarters, this paper analyzes the effects of adding one quarter (13 weeks) as opposed to adding more than 13 quarters (170 weeks) to benefit duration. Moreover, this paper provides evidence on the effects of large and small changes in benefit duration on unemployment duration, duration of job search, and post-unemployment job quality.

The outline of this paper is as follows. Section I provides background on the unemployment insurance system, on the regional extended benefit program, and on the early retirement rules in Austria. Section II discusses the dataset. Section III provides descriptive evidence on the effects of large benefit extensions on unemployment duration. Section IV provides the regression analysis of the effects of both large and small extensions of benefit duration on unemployment duration and post-unemployment job quality, and section $\mathrm{V}$ concludes this paper with a summary of our findings.

\section{Background}

This section provides a brief overview of the three features of the Austrian social security regulations that are relevant for this paper. First, the potential duration of unemployment benefit (UB) payments is dependent on previous experience but also on age at the beginning of the unemployment spell as of August 1989. Benefit duration for the age group 40-49 is 39 weeks if the unemployed has been employed 312 weeks within the last 10 years prior to the 
current spell. For the age group 50 and older, UB-duration is 52 weeks if the unemployed has been employed for at least 468 weeks within the last 15 years.

Second, the regional extended benefit program (REBP) provided 209 weeks of UB if a job seeker satisfied, at the beginning of his or her unemployment spell, each of the following criteria: (i) age 50 or older; (ii) a continuous work history (780 employment weeks during the last 25 years prior to the current unemployment spell); (iii) location of residence in one of 28 selected labor market districts since at least 6 months prior to the claim; and (iv) start of a new unemployment spell after June 1988 or spell in progress in June 1988. The REBP was initially expected to be in effect until December 1991. However, the Austrian parliament decided at the end of 1991 to extend the program until August 1993 when it was eventually abolished.

A third measure affecting older job seekers is Sonderunterstützung (special income support). The special income support program provides benefits for at most one year; benefits are $25 \%$ higher than unemployment benefits capped from above by the pension benefit the individual is expected to receive from the pension system. Special income support is available to men aged 59 years or older and women aged 54 years or older thus serving as a bridge into regular early retirement, available at age 60 to men and age 55 to women.

\section{Data}

The empirical analysis uses administrative information on all individuals entering unemployment from a job in the non-steel sector in the time period 8/1989 until 7/1991 for the regional extended benefit analysis. This time period covers the longest possible time period where REBP is introduced but no other changes in benefit entitlement take place. The analysis furthermore focuses on individuals with a 'continuous' work history. A continuous work history is defined as a career with a ratio of actual to potential work experience since the year 1972 of at least 0.7 (the REBP requires a ratio of 0.6). This ensures that only workers 
who satisfy the work experience requirement with a very high probability are included in the sample.

The data contain information on the month and year of birth, and month and year of entry into unemployment. This allows calculating the age at entry into unemployment by counting the number of years and months of a person's life completed before entering unemployment. The empirical analysis restricts attention to individuals aged 46 years to 53 years (and 11 months) at the beginning of the unemployment spell. This is the only age bracket where both women and men do not have access to special income support on the first day of the unemployment spell.

The resulting dataset contains information on 40,028 individuals entering unemployment from a regular job in the non-steel sector. On average these job seekers remain unemployed for 25 weeks. About $81 \%$ of all of all spells end in a transition to a regular job. Of the remaining spells $1 \%$ are right censored at the end of the observation window, $4 \%$ are right censored due to a break in the unemployment spell exceeding 4 weeks, $5 \%$ exit to long-term sickness (exceeding 3 months), and $8.5 \%$ exit to early retirement programs. Those finding a job, search for a job during 11 weeks on average, whereas those who do not leave for a job remain unemployed for 85 weeks on average. The data contain information on daily earnings, that is earnings divided by days worked. The change in log daily earnings between the preand the post unemployment job is 0.057 , so job seekers gain about 5.7 percent in terms of daily earnings. Note that this gain could also reflect changes in hours worked rather than changes in wages.

\section{Descriptive Evidence on the Effects of Extended Benefits}

Figures 1 and 2 provide graphical evidence on the effects of extending unemployment duration from 39 weeks to 209 weeks in regions with REBP. Figure 1 shows average unemployment duration for men in the age bracket 46 to 53 years. Individuals who have not 
yet reached the age threshold of 50 years remain unemployed for 13 weeks on average. In contrast, average unemployment duration exceeds 26 weeks in almost all age cells for individuals aged 50 years or older. There is a significant discontinuity in average unemployment duration that occurs between individuals aged 49 years and 4 quarters and individuals aged 50 years and 1 quarter. This suggests that there is a strong effect of adding 170 weeks of unemployment benefits on the average duration of unemployment spells.

Figure 2 concentrates on women entering unemployment in treated regions in the age bracket 46 to 53 years and it displays two striking facts. First, there is a very salient increase in unemployment duration at the age 50 threshold. Whereas the women who are slightly younger than the threshold leave unemployment on average after about 16 weeks, women who are slightly older than the threshold do not exit unemployment for more than 130 weeks on average. Thus, there appears to be a strongly significant increase in unemployment duration by at least 110 weeks. Second, in the age bracket 50 to 53 years, there is a very strong decrease in average unemployment duration from more than 130 weeks (age 50 years and 1 quarter) to less than 52 weeks (age 53 years and 4 quarters). This evidence is consistent with an interpretation that a substantial fraction of eligible women remain unemployed until they turn 54, the minimum age required in the special income support program.

\section{Econometric Results}

Table 1 reports the results of a series of regression discontinuity analyzes that are based on a model that identifies the treatment effect allowing for potentially different linear trends in age on both sides of the threshold (see Lalive 2006).

The first two columns in row A of Table 1 shows the effects of extended benefits on unemployment duration replicating the graphical analysis in the previous section. Columns 3 and 4 report the effects of extending benefits by 13 weeks for men and women, respectively. 
Surprisingly, there is no effect of adding a quarter to the maximum benefit duration for men. In contrast, average unemployment duration increases by about 6 weeks among women.

Row B in Table 1 studies the effects of extended benefits on the fraction leaving unemployment for a job. The baseline probability of leaving unemployment for a job is about 0.9 for all groups (not shown in Table 1). Extending unemployment benefits by 170 weeks reduces the fraction leaving for a job by 4.4 percentage points among men living in treated regions. The effects of extended benefits on transitions to jobs are much stronger among women. The extended benefits policy leads to a reduction in transitions to job by 53 percentage points. This is in line with the early retirement provisions that are available to women once they turn 54 years old. In the regions that are not covered by REBP, extending benefits by 13 weeks does not appear to affect the final job search destination. Both among women and men, the share leaving for a job remains unchanged.

Row $\mathrm{C}$ in Table 1 displays the effects of extended benefits on the duration of search for a regular job. Strong benefit extensions lead to relatively weak extensions of the duration until a regular job is found. Duration until a job is taken increases by about 1.7 weeks among men. The corresponding effect is about 2.9 weeks for women. Thus, even though the maximum benefit duration is increased by more than 3 years, the duration of successful job search increases by less than 0.02 weeks per additional week of benefits granted. What happens with weak benefit extensions? The 13 week benefit extension does not affect the duration of successful job search among men but it does prolong the job search duration by about 3 weeks among women.

The analysis in Row $\mathrm{C}$ of Table 1 is based on the sub-sample of job seekers who find a job at the end of the unemployment spell, a potentially selective sub-sample. Note, however that wee do not find any evidence of a discontinuity in the pre-unemployment earnings at the 
age threshold 50 years, except for the male job seekers living in treated regions. Thus there is no strong evidence for selectivity with respect to the previous wage.

Row $\mathrm{D}$ in Table 1 provides evidence on the effects of extended benefits on job quality. In particular, the analysis is based on the change in the log daily earnings in the post unemployment job compared to the pre unemployment job. In line with recent findings by Card et al. (2006) and Van Ours and Vodopivec (2006a), we do not find that extended benefits affect average daily wages.

\section{Concluding remarks}

This paper studies the effects of small (13 weeks) and large (170 weeks) extensions of the duration of unemployment benefits in Austria. Findings indicate that large benefit extensions increase unemployment duration, reduce transitions to regular jobs, increase the duration until a new job is taken but do not have a discernible effect on post-unemployment job quality as measured by earnings in the new job. In contrast, small benefit extensions do not necessarily increase unemployment duration. While there is a statistically significant increase in duration for women, no corresponding effect is present for men. Small benefit extensions do not affect transitions to job nor job quality but they do prolong the duration of successful job search.

In sum, this analysis offers at least two conclusions. First, extended benefits do not affect the duration of successful job search very strongly. Changes to benefit duration appear to inflate the duration until a job seeker enters another social insurance program. Second, changes in benefit duration do not affect the quality of post-unemployment jobs but large changes in benefit duration appear to reduce the number of transitions to regular jobs. 


\section{References}

Card, David E. and Phillip B. Levine, "Extended Benefits and the Duration of UI Spells:

Evidence from the New Jersey Extended Benefit Program," Journal of Public Economics, 2000, $78(1), 107-138$.

Card, David E. , Raj Chetty, and Andrea Weber, "Cash-on-Hand and Competing Models of Intertemporal Behavior: New Evidence from the Labor Market," Mimeo, UC Berkeley 2006.

Lalive, Rafael, "How do Extended Benefits Affect Unemployment Duration? A Regression Discontinuity Approach,” Mimeo, 2006, University of Lausanne.

Lalive, Rafael and Josef Zweimüller, "Benefit Entitlement and Unemployment Duration: The Role of Policy Endogeneity,” Journal of Public Economics, 2004, 88 (12), 2587-2616.

Nickell, Stephen and Richard Layard, "Labor Market Institutions and Economic Performance," in Orley Ashenfelter and David Card, eds., Handbook of Labor Economics, Vol. 3, Amsterdam: North-Holland, 1999, pp. 1801- 1863.

Van Ours, Jan C. and Milan Vodopivec, "Duration of Unemployment Benefits and Quality of Post-Unemployment Jobs: Evidence from a Natural Experiment ," Working Paper, Tilburg University 2006a.

Van Ours, Jan C. and Milan Vodopivec, "How Shortening the Potential Duration of Unemployment Benefits Entitlement Affects the Duration of Unemployment: Evidence from a Natural Experiment," Journal of Labor Economics, 2006b, 24(2006), 351-378. 
Figure 1: The Effect of 170 Weeks of Extended Benefits for Men

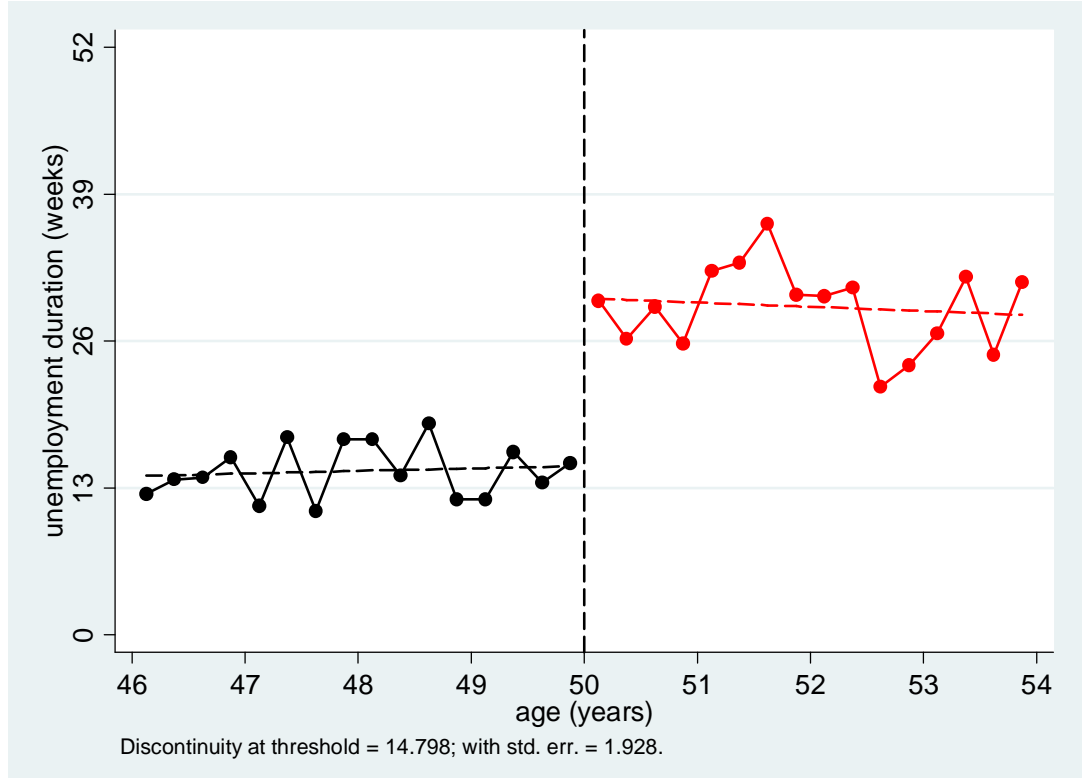

Source: Own calculations, based on Austrian Social Security Data.

Figure 2: The Effect of 170 Weeks of Extended Benefits for Women

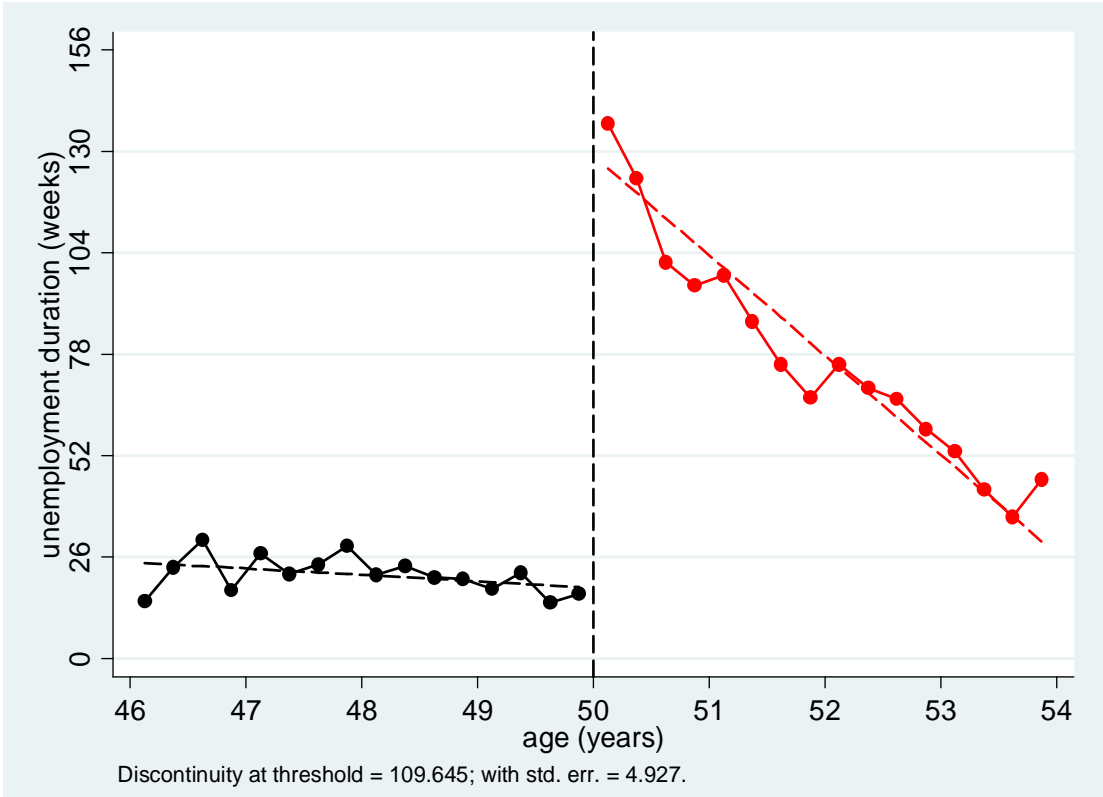

Source: Own calculations, based on Austrian Social Security Data. 
Table 1: The Effects of Extended Benefits on Labor Market Outcomes

\begin{tabular}{lcccc}
\hline Benefits extended by (weeks) & 170 & 170 & 13 & 13 \\
Sample & Men & Women & Men & Women \\
A. Unemployment duration (weeks) & 14.798 & 109.645 & -0.326 & 6.067 \\
& $(1.717)^{* * *}$ & $(6.088)^{* * *}$ & $(0.973)$ & $(2.314)^{* *}$ \\
B. Fraction leaving for job & -0.044 & -0.526 & -0.011 & 0.061 \\
& $(0.013)^{* * *}$ & $(0.041)^{* * *}$ & $(0.007)$ & $(0.038)$ \\
C. Duration until exit to job (weeks) & 1.542 & 2.924 & -0.585 & 2.935 \\
& $(0.471)^{* * *}$ & $(1.087)^{* * *}$ & $(0.392)$ & $(0.811)^{* * *}$ \\
D. Change in log Earnings & -0.000 & 0.010 & -0.001 & -0.020 \\
& $(0.006)$ & $(0.008)$ & $(0.008)$ & $(0.016)$ \\
\hline \hline
\end{tabular}

Notes: $\quad$ Each row in table 1 contains estimated effect of extended benefits. Age-cell cluster robust standard error in parentheses.

Source: Own calculations, based on Austrian Social Security Data. 